\title{
Chapter 5 \\ SLM Production Systems: Recent Developments in Process Development, Machine Concepts and Component Design
}

\author{
Reinhart Poprawe, Christian Hinke, Wilhelm Meiners, \\ Johannes Schrage, Sebastian Bremen and Simon Merkt
}

\begin{abstract}
The emerging Additive Manufacturing (AM) and especially the Selective Laser Melting (SLM) technologies provide great potential for solving the dilemma between scale and scope, i.e. manufacturing products at mass production costs with a maximum fit to customer needs or functional requirements. Due to technology intrinsic advantages like one-piece-flow capability and almost infinite freedom of design, Additive Manufacturing was recently even described as "the manufacturing technology that will change the world". Due to the complex nature of production systems, the technological potential of AM and especially SLM can only be realised by a holistic comprehension of the complete value creation chain, especially the interdependency between products and production processes. Therefore this paper aims to give an overview regarding recent research in machine concepts and process development as well as component design which has been carried out within the cluster of excellence "Integrative production technology for high wage countries".
\end{abstract}

\subsection{Introduction}

The overall objective of "ICD-A Individualised Production" within the Cluster of Excellence is the resolution of the dichotomy between scale and scope, i.e. manufacturing products at mass production costs with a maximum fit to customer needs or functional requirements (Schleifenbaum 2011).

The emerging Additive Manufacturing (AM) and especially the Selective Laser Melting (SLM) technologies provide great potential for solving this dilemma. With this layer-based technology the most complex products can be manufactured without tools or moulds. The 3D-CAD model gets sliced layer wise for computing the scan tracks of the laser beam. In a first manufacturing step powder material

R. Poprawe $\cdot$ C. Hinke $(\varangle) \cdot$ W. Meiners $\cdot$ J. Schrage $\cdot$ S. Bremen $\cdot$ S. Merkt Fraunhofer Institute for Laser Technology ILT, Steinbachstr. 15, 52074 Aachen, Germany e-mail: christian.hinke@ilt.fraunhofer.de

(C) The Author(s) 2015

C. Brecher (ed.), Advances in Production Technology,

Lecture Notes in Production Engineering, DOI 10.1007/978-3-319-12304-2_5 


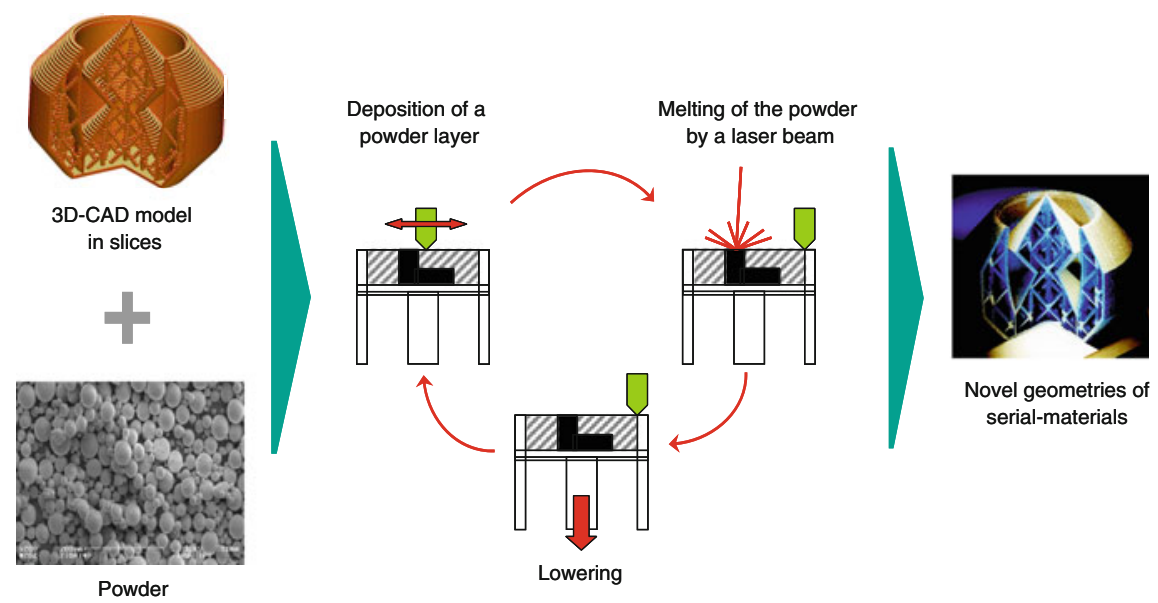

Fig. 5.1 Schematic representation of the SLM process

(typically in a range of $25-50 \mu \mathrm{m}$ ) is deposited as a thin layer (typically 30-50 $\mu \mathrm{m}$ ) on a substrate plate. According to the computed scan tracks the laser beam melts the powder which is solidified after melting. The substrate plate is lowered and another powder layer is deposited onto the last layer and the powder is melted again to represent the parts geometry (Fig. 5.1). These steps are repeated until almost $100 \%$ dense parts with serial-identical properties are manufactured with the SLM process directly from the 3D-CAD model (Meiners 1999; Over 2003; Schleifenbaum 2008).

Due to technology intrinsic advantages like one-piece-flow capability and almost infinite freedom of design, Additive Manufacturing was recently even described as "the manufacturing technology that will change the world" (Economist 2011) and several international research groups are working on this topic (Gibson 2010; Hopkinson 2005; Lindemann 2006).

AM technology in general and in particular SLM is characterised by a fundamentally different relation of cost, lot size and product complexity compared to conventional manufacturing processes (Fig. 5.2). There is no increase of costs for small lot sizes (in contrast to mould-based technologies) and no increase of costs for shape complexity (in contrast to subtractive technologies).

For conventional manufacturing technologies such as die casting the piece cost depends on the lot size. For increasing lot sizes the piece costs are decreasing due to economies-of-scale. Because lot depended fixed costs (e.g. tooling costs) are very low for AM, AM enables the economic production of parts in small lot sizes (Individualisation for free). Innovative business models such as customer co-creation can be implemented using this advantage of AM technologies (Fig. 5.2 left).

The more complex a product is, the piece cost for manufacturing increase. For AM this relation is not applicable. The nearly unlimited geometric freedom that is offered through AM makes the piece cost almost independent from product complexity. In some cases manufacturing costs can even decrease due to lower build-up 


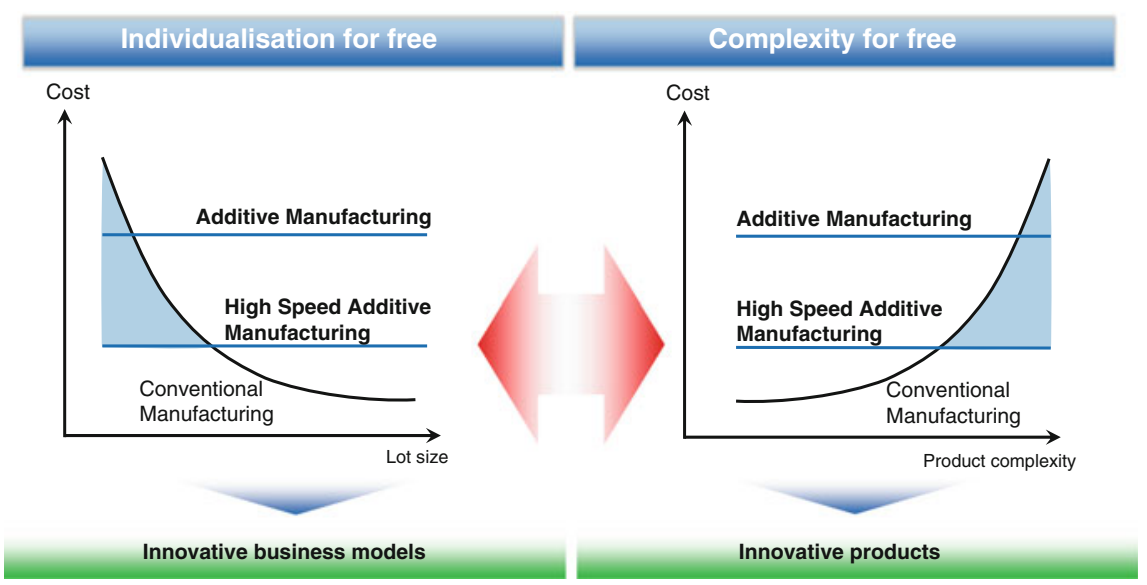

Fig. 5.2 Innovative business models and innovative products enabled by Additive Manufacturing

volumes of optimized products with high geometric complexity. Topology optimisation is one design approach to save weight while functionally adapting the product design to predefined load cases (Huang 2007). These different relations between piece cost and product complexity offer a unique capability for AM to manufacture innovative products perfectly adapted to the specific technological requirements through the integration of lattice structures (Fig. 5.2 right).

Due to the complex nature of production systems, the technological potential of AM and especially SLM can only be realised by a holistic comprehension of the complete value creation chain, especially the interdependency between products and production processes.

Therefore this paper aims to give an overview regarding recent research in machine concepts and process development as well as component design which has been carried out within the cluster of excellence "Integrative production technology for high wage countries".

\subsection{SLM Machine Concepts}

State-of-the-art SLM machines are typically equipped with a $400 \mathrm{~W}$ laser beam source and a build space of $250 \times 250 \times 300 \mathrm{~mm}^{3}$. There are different ways to increase the productivity of SLM machines in terms of process build rate. In general the productivity can be increase by the following measures:

Increase of laser power to increase the scanning speed, use bigger layer thickness and bigger beam diameter to increase the build-up speed. 


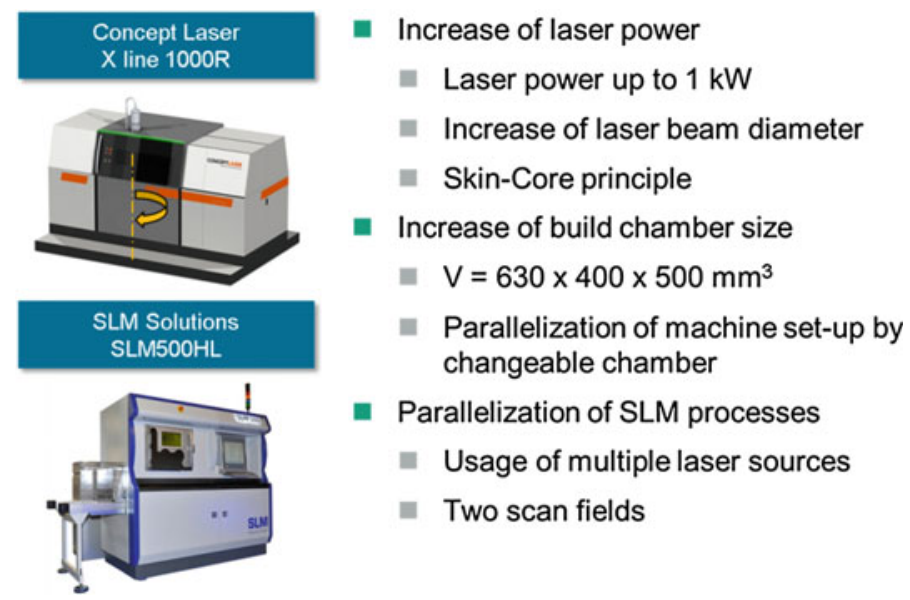

Fig. 5.3 SLM machine concepts for increasing the productivity

By increasing the build volume more parts can be manufactured in one build job. Hence, the number of necessary machine set-up and part removal procedures can be reduced.

Another method to increase the productivity is the parallelisation of the SLM process by using multiple laser beam sources and multi laser-scanning-systems in one machine. Either the build area can be multiplied or one build space can be processed by multi lasers and scanning-systems at the time.

The SLM machine X-line 1000R by Concept Lasers that was presented at the Euromold (2012) comprises a big build space of $630 \times 400 \times 500 \mathrm{~mm}^{3}$ that can be processed with one laser-scanning-system that is moved above the build platform (Fig. 5.3). This machine is equipped with two process chambers that are rotatable. One process chamber can be prepared for the next build job while in the second one the SLM process can take place (Concept Laser 2014).

Another example of a SLM machine with an increased build volume is the SLM machine SLM500HL by SLM Solutions. The build volume is $500 \times 280 \times 335 \mathrm{~mm}^{3}$. The process chamber can be moved inside and out of the machine. The preparation of the build space can be done outside of the process chamber. The SLM machine SLM500HL can be equipped with up to 4 laser beam sources with that the build are can be processed at the same time. Furthermore the so called skin-core build strategy can be performed. The beam with a small diameter $\left(\mathrm{d}_{\mathrm{S}}=80 \mu \mathrm{m}\right)$ and up to a laser power of $400 \mathrm{~W}$ is used to build up the outer shape of the parts (skin). A laser beam with big beam diameter $\left(\mathrm{d}_{\mathrm{S}}=700 \mu \mathrm{m}\right)$ and laser power up to $1 \mathrm{~kW}$ is used to build the inner core of the part (core). So the build up speed can be elevated while maintaining the part accuracy (SLM Solutions 2014). 


\subsubsection{Valuation Method for SLM Machine Concepts}

For the comparison and the evaluation of different SLM machine concepts not only the investment costs of the machine have to be taken into account but also the costs that are caused during the whole utilization time. Therefore a suitable valuation method has to be found.

One approach is to analyse the life cycle costs (such as the machine price, maintenance costs and energy costs) and the cost of the life cycle performance (such as "laser-on-time" to "laser-off time").

In typical cost models for SLM investment evaluation the machine hourly rate is used to calculate the price for the SLM manufactured part. Furthermore, cost and time factors for preparation and follow steps may be included in the calculation (Rickenbacher 2013).

In a life cycle cost analysis, including the identification of cost drivers is carried out for additively manufactured components (Lindemann 2012). As the main cost driver, the machine costs $(73 \%)$ and material costs $(11 \%)$ were followed by the cost of any demand (7\%) and preparatory work (4\%) are identified.

In none of those cost models the influence of the SLM machine concept (build space, laser power, etc.) is analysed in detail. The cost drivers of those SLM machines are undiscovered.

A life cycle cost based model is developed to create a possibility to compare different SLM machine concepts.

In Fig. 5.4 the costs for molten powder material volume $\left(€ / \mathrm{cm}^{3}\right)$ are shown as a function of the total laser power used in the SLM process. The allocation of the total costs can be divided into the investment costs (machine costs, costs for laser) and variable costs (powder material, energy costs, gas costs etc.). In this case the operating time of the machine is seven years at a capacity utilization of $70 \%$. The

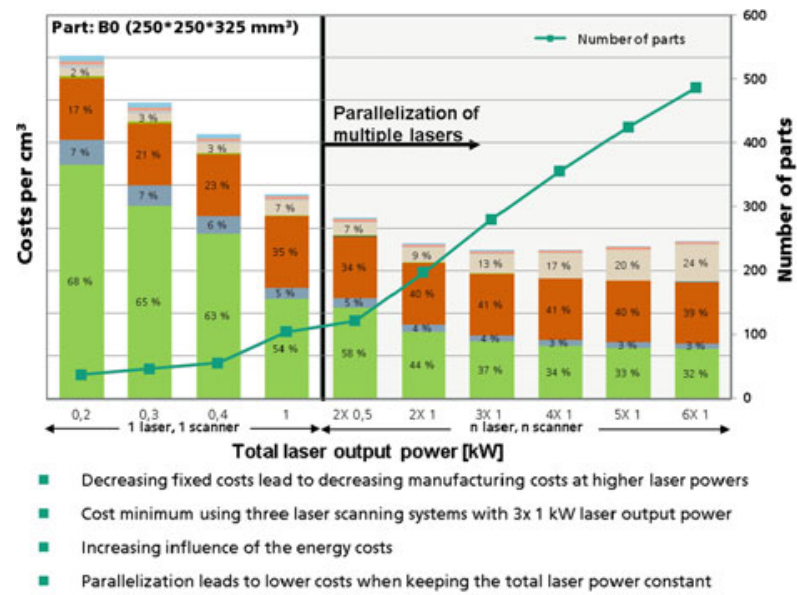

\begin{tabular}{|c|c|}
\hline Fixed costs & Variable costs \\
\hline Machine & Fiter \\
\hline \multirow{6}{*}{ Senvice } & Wage \\
\hline & Energy \\
\hline & Inert gas Flow \\
\hline & Inert gas Flooding \\
\hline & Substrate plate \\
\hline & Material \\
\hline Machine component & Characteristic \\
\hline Laser & variable \\
\hline Opties & $\begin{array}{c}n \text { S Scanner } \\
n \text { F-Theta-Lens }\end{array}$ \\
\hline Building volume (XYZ) & $250^{\prime} 250^{\prime} 325 \mathrm{~mm}^{3}$ \\
\hline Recoating & unidirectional \\
\hline Material management & manually \\
\hline Fiter system & internal \\
\hline Cost element & Rate \\
\hline Operating time & 7 years \\
\hline Machine utilization & $70 \%$ \\
\hline Service costs & $1,4 \%$ of machine price \\
\hline Powder material costs & $50 \mathrm{E} / \mathrm{kg}$ (Alsi10Mg) \\
\hline Personnel costs & $80 € \mathrm{~h}$ \\
\hline
\end{tabular}

Fig. 5.4 Influence of total laser power on SLM manufactured part costs 
build space is considered with $250 \times 250 \times 325 \mathrm{~mm}^{3}$ and the part to be manufactured is a space-filling solid cuboid of the dimension of $250 \times 250 \times 325 \mathrm{~mm}^{3}$. Here only one laser-scanning system is used up to $1 \mathrm{~kW}$ total laser power. At total laser power $>1 \mathrm{~kW}$ the SLM process is parallelised by integrating multiple laser scanner systems in one SLM machine.

The findings are: The costs of molten material are reduced when using higher total laser power due to increasing productivity. The minimum costs are found at a total laser power of $3 \mathrm{~kW}$, which is provided by $3 \times 1 \mathrm{~kW}$ laser and scanner systems. With further increase of the total laser power $(>3 \mathrm{~kW})$ and hence integrating more laser beam sources and more laser-scanning systems the increasing energy costs lead to an increase in total manufacturing costs.

The cost of the SLM machine itself represents the largest share of the total part manufacturing costs. In Fig. 5.5 the effects of the machine build volume in relation to the machine costs are illustrated. At a same physical height the enlargement of the space in the lateral plane (X and Y direction) has a stronger influence on the machine costs, as a space, which is increased by increasing the height ( $\mathrm{Z}$ direction). $\mathrm{Up}$ to a ratio of three for the Z-height to its $\mathrm{X}-\mathrm{Y}$-area cost savings can be identified. At ratios greater than 3 , only minor changes in the costs are observed.

\subsubsection{SLM Machine Concept Parallelization}

Within the framework of the Cluster of Excellence a multi-scanner-SLM machine is designed and implemented. In this system two lasers and two scanners are

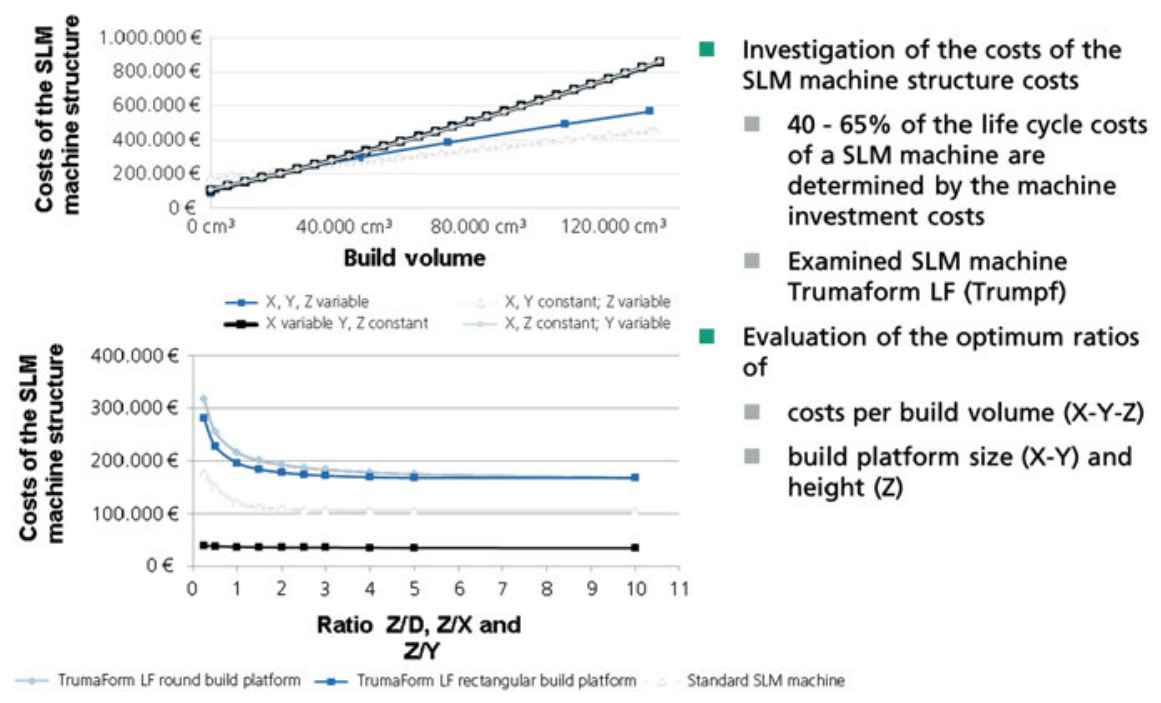

Fig. 5.5 Impact of build volume on the SLM manufactured part costs 


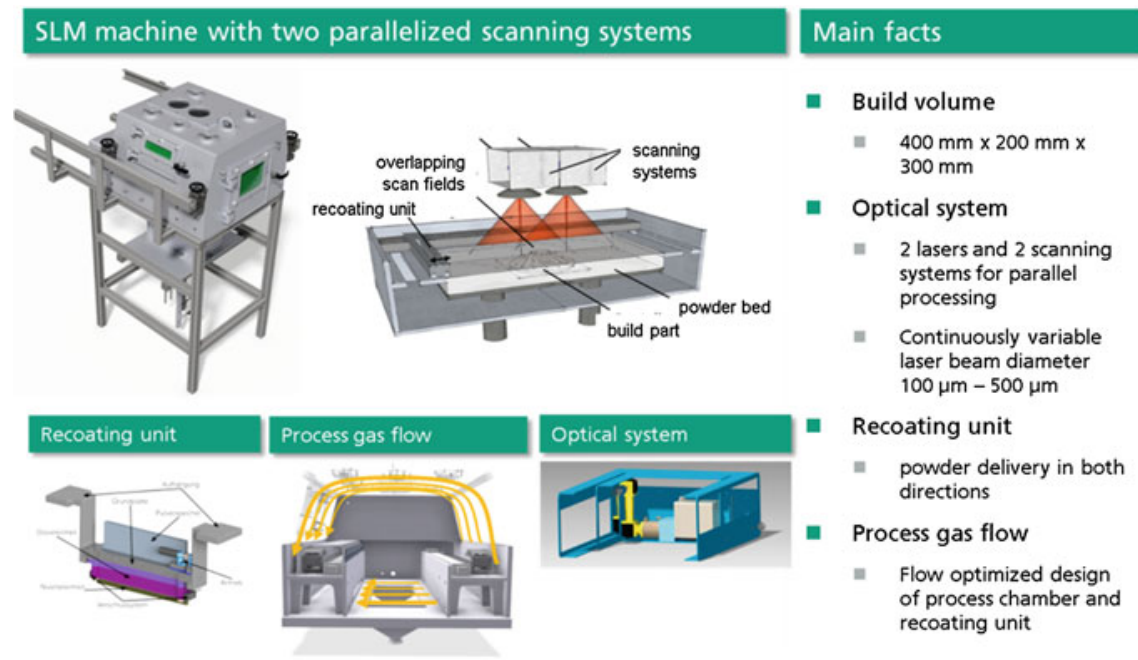

Fig. 5.6 SLM machine concept of parallelization

integrated. These two scanners can be positioned to each other that both either scan two fields on its own (double-sized build space) or one scan field is processed with two scanners simultaneously (Fig. 5.6).

With these multi-scanner systems new scanning strategies can be developed and implemented (Fig. 5.7).

Scanning strategy 1: Both scan fields are positioned next to each other with a slight overlap. This results in a doubling of the build area. By using two laser beam

\section{Strategy 1: Parallel processing of two scanning fields}

Scanning strategy 1: Parallel processing of two
scanning fields

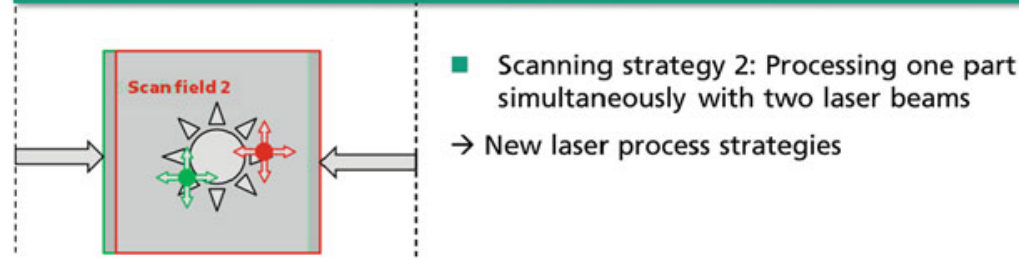

Fig. 5.7 New SLM laser processing strategies with two lasers and two scanning systems 
sources and two laser-scanning systems both scan fields can be processed at the same time. In this case the build-up rate is doubled.

Scanning strategy 2: The two laser beam sources and the two laser-scanning systems expose the same build area. Again, a doubling of the build-up rate is achieved. In addition, new process strategies may be developed: A laser beam is used for preheating the powder material that is followed by a second laser beam that melts the powder afterwards.

\subsection{Process Development}

Recent developments in SLM machines show that the machine supplier offer SLM systems with increased laser power $\left(\mathrm{P}_{\mathrm{L}} \leq 1 \mathrm{~kW}\right)$. The aim is to increase the process speed and thereby the productivity of the SLM process. However, by the use of a beam diameter of approx. $100 \mu \mathrm{m}$, which is commonly used in commercial SLM systems, the intensity at the point of processing is significantly increased due to the use of increased laser power. This effect results in spattering and evaporation of material and therefore in an unstable and not reproducible SLM process. For this reason the beam diameter has to be increased in order to lower the intensity in the processing zone. In this case the melt pool is increased and the surface roughness of the manufactured part is negatively influenced. To avoid these problems the so-called skin-core strategy (Fig. 5.8) is used, whereby the part is divided into an inner core and an outer skin (Schleifenbaum 2010). Different process parameters and focus diameters can be designated to each area. The core does not have strict limitations or requirements concerning the accuracy and detail resolution. Therefore, the core area can be processed with an increased beam diameter $(\mathrm{ds}=400-1000 \mu \mathrm{m})$ and an increased laser power; thus resulting in an increased productivity. In contrast, the skin area is manufactured with the small beam diameter $(\mathrm{ds}=70-200 \mu \mathrm{m})$ in order to assure the accuracy and surface quality of the part.

By increasing the beam diameter and adapting the process parameters the cooling and solidification conditions change significantly in comparison to the conventional SLM process. Therefore the microstructure and the resulting
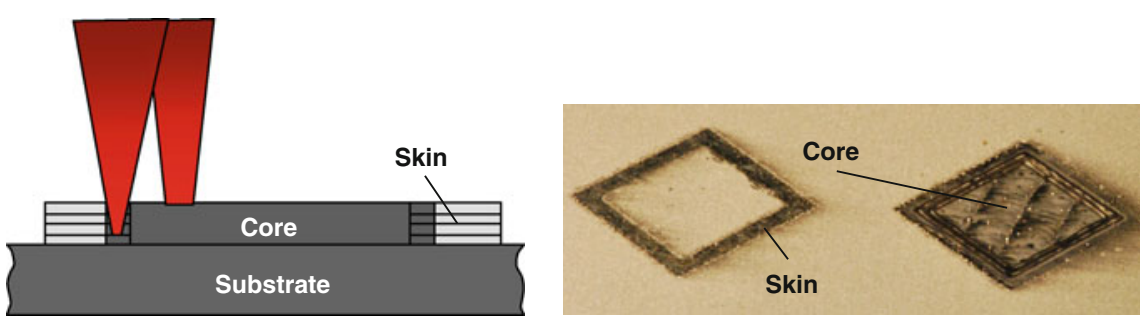

Fig. 5.8 Principle skin-core strategy 


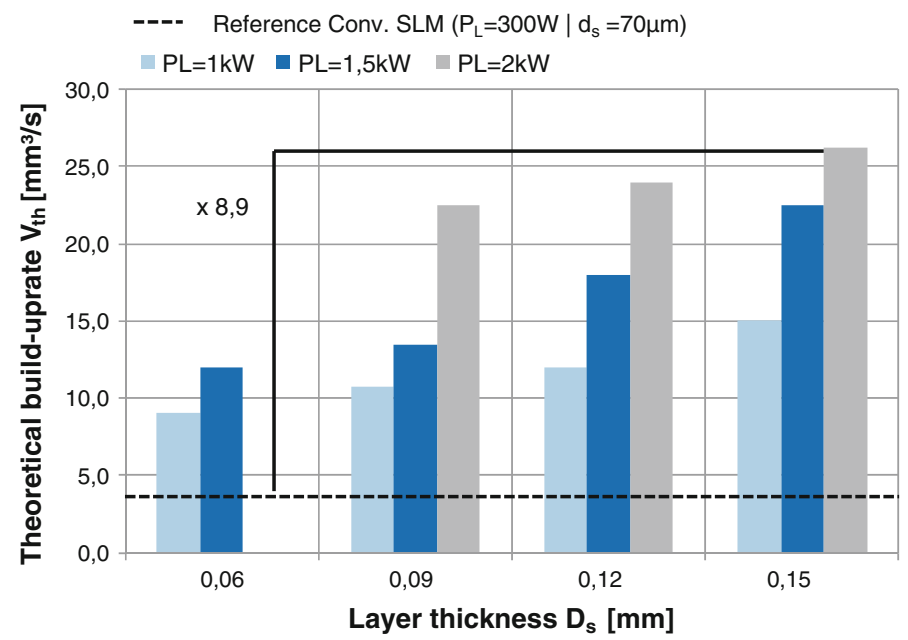

Fig. 5.9 Theoretical build up rate according to layer thickness and laser power processing the tool steel 1.2709

mechanical properties have to be investigated in detail. These investigations are done for the maraging tool steel 1.2709 within the Cluster of excellence.

The first step is to investigate process parameters on cubic test samples which have a averaged density of $\geq 99.5 \%$. Therefore a SLM machine setup with a laser beam diameter of $\mathrm{d}_{\mathrm{s}}=80 \mu \mathrm{m}$ (Gaussian beam profile) and $\mathrm{d}_{\mathrm{s}}=728 \mu \mathrm{m}$ (Top-hat beam profile) is used. The results for the achieved theoretical build-up rate which is calculated by the product of hatch distance, layer thickness and scanning velocity is illustrated in Fig. 5.9. It can be observed that by the increase of the laser power from $300 \mathrm{~W}$ up to $\mathrm{P}_{\mathrm{L}}=1 \mathrm{~kW}$ and an adaption of the process parameters layer thickness and scanning velocity the theoretical build up rate can be increased from $3 \mathrm{~mm}^{3} / \mathrm{s}$ to $15 \mathrm{~mm}^{3} / \mathrm{s}$. A further increase of the laser power up to $\mathrm{P}_{\mathrm{L}}=2 \mathrm{~kW}$ results in an increase of the theoretical build-up rate to $26 \mathrm{~mm}^{3} / \mathrm{s}$ (factor 8,9 ). These investigations show that it is possible with the use of increased laser power up to $\mathrm{P}_{\mathrm{L}}=2 \mathrm{KW}$ to heighten the theoretical build-up rate and thereby the productivity significantly.

After the investigation of process parameters the microstructure for the manufactured test samples is investigated. Especially the transition zone between skin and core area has to be investigated in order to assure a metallurgical bonding between skin and core area. Due to the different layer thicknesses $\left(D_{\mathrm{s}, \mathrm{skin}}=30 \mu \mathrm{m}\right.$, $\left.\mathrm{D}_{\mathrm{s}, \mathrm{core}}=60-150 \mu \mathrm{m}\right)$ the scanning strategy has to be adapted.

Figure 5.10 shows etched cross section of the skin and core area as well as the transition zone between skin and core area. It can be observed that due to the use of the increased beam diameter the melt pool size is significantly increased. In addition the transition zone between skin and core area shows no defects and metallurgical bonding. As a result it can be noted that by the use of the skin-core strategy, test 


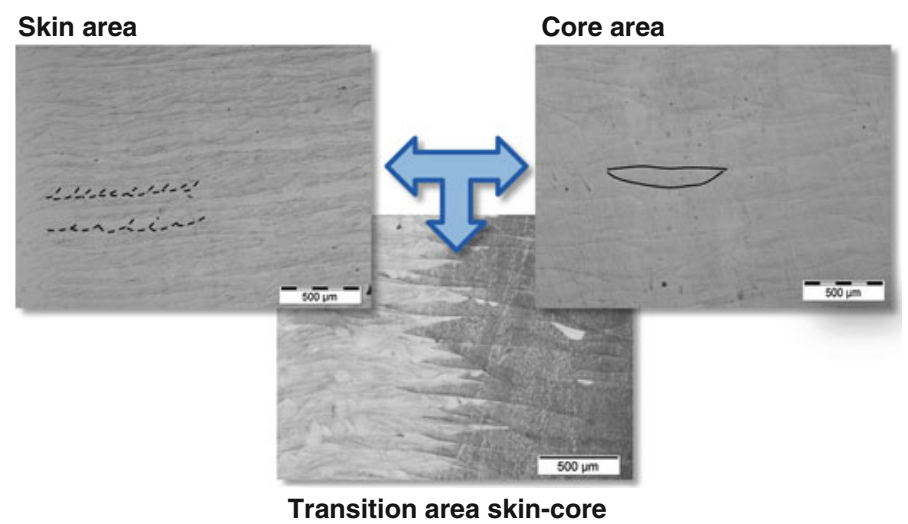

Fig. 5.10 Cross section of skin and core area as well as transition zone between skin and core area

samples, consisting of skin and core area, with a density $\geq 99.5 \%$ can be manufactured.

In order to investigate the properties of the additive manufactured parts mechanical tests are carried out. Therefore tensile test specimens with the dimension B5x25 according to DIN50125 are manufactured and afterwards heat treated. For each parameter five tensile test specimens are manufactured and the averaged values for tensile strength $\mathrm{Rm}$, yield strength $\mathrm{Rp} 0,2$ and the breaking elongation are measured.

Figure 5.11 shows the results of the tensile tests according to the employed process parameters. It can be observed that for conventional SLM using $300 \mathrm{~W}$ laser power at $30 \mu \mathrm{m}$ layer thickness a tensile strength $\mathrm{Rm}=1060 \mathrm{~N} / \mathrm{mm}^{2}$ is achieved. By the use of the heat treatment the tensile strength is increased up to $\mathrm{Rm}=1890 \mathrm{~N} / \mathrm{mm}^{2}$. In contrast the heat treatment leads to an reduced breaking

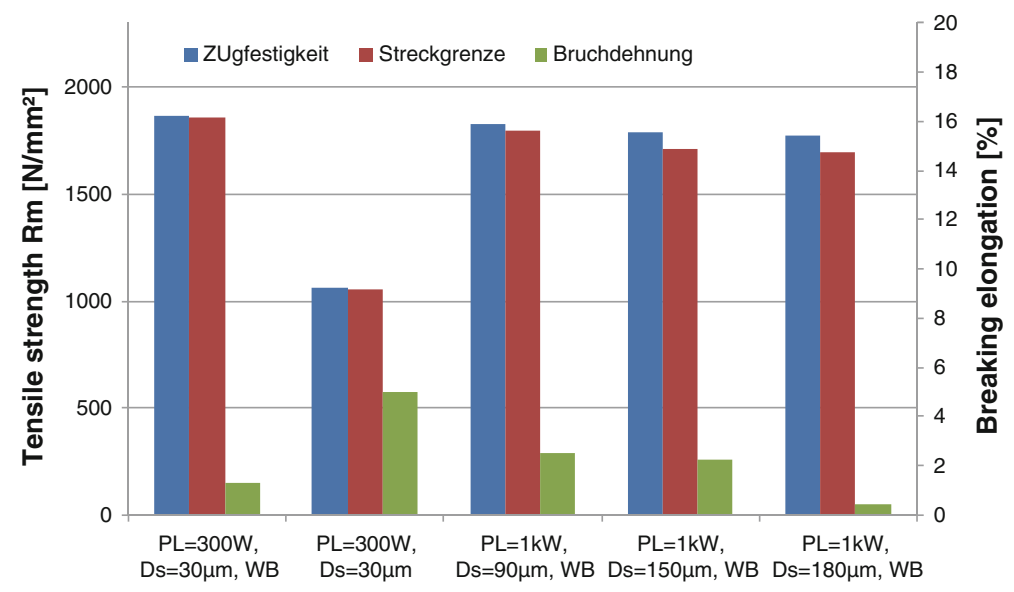

Fig. 5.11 Results tensile test according to process parameters 
elongation $(5 \% \rightarrow 1.32 \%)$. These results are used as reference for the tensile test specimen manufactured by the use of increased laser power. The results in Fig. 5.4 show that by an increase of the laser power up to PL $=1 \mathrm{~kW}$ and an adaption of process parameters as well as the use of a heat treatment a tensile strength of $\mathrm{Rm}=1824 \mathrm{~N} / \mathrm{mm}^{2}$ is achieved. In addition the breaking elongation using $\mathrm{PL}=1 \mathrm{~kW}$ shows a value of $2.53 \%$. A further increase of the laser power up to $\mathrm{PL}=1.5 \mathrm{~kW}$ leads to tensile strength of $1790 \mathrm{~N} / \mathrm{mm}^{2}$ with a breaking elongation of $2.24 \%$. These results show that the mechanical properties for the maraging steel 1.2709 , processed with a laser power up to $1.5 \mathrm{~kW}$, lead to mechanical properties which are in the same range as the properties for conventional SLM (PL $=300 \mathrm{~W})$.

\subsection{Functional Adapted Component Design}

As explained in Fig. 5.2 Additive Manufacturing in general and especially SLM provides a great potential for innovative business models and innovative products or components. Due to technology intrinsic advantages like "Individualisation for free" and "Complexity for free", SLM is the technology of choice for the production of functional adapted products or components in small or medium lot sizes.

In order to raise this potential, design methods has to be adapted to the potential of Additive Manufacturing (e.g. topology optimisation) or even new design methods has to be developed (e.g. lattice structures).

The following chapter shows recent results in the field of topology optimisation and lattice structure design.

\subsubsection{Topology Optimisation and SLM}

In contrast to subtractive manufacturing methods like machining, the main cost driver of the SLM process is the process time needed to generate a certain amount of part volume. As a consequence, reducing the part volume to the lowest amount needed to absorb the forces of the use case, is an important factor to increase the productivity of the SLM process. Topology optimisation is an instrument to design load adapted parts based on a FEM-analysis. The load cases including forces and clamping need to be very clear to get the best results possible. In an iterative process the topology optimisation algorithm calculates the stress level of each FEM element. Elements with low stresses are deleted until the optimisation objective/ criterion (e.g. weight fraction) is reached. The topology optimisation usually results in very complex parts with 3D freeform surfaces and hollow and filigree structures. The commonly used way to fabricate these part designs is a reconstruction considering process restrictions of conventional manufacturing methods like casting or machining, resulting in a lower weight reduction. SLM opens opportunities to fabricate complex optimisation designs without any adjustments after optimisation. 


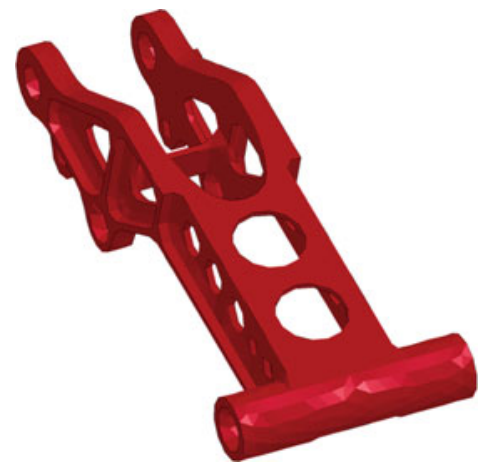

Conventional design

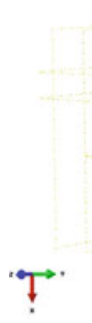

Design space and frozen regions (red)

Fig. 5.12 Kinematics lever of a business class seat

The reduction of weight is an important factor in aerospace industry (Rehme 2009). Fuel consumption is mainly determined by the weight of the aircraft. An aircraft seat manufacturer is investigating the opportunities to save weight in their business class seats through SLM. One part of the seat assembly, a kinematics lever, was selected to investigate the potential of the direct fabrication of topology optimisation results via SLM (Fig. 5.12).

In a first step the maximum design space and connecting interfaces to other parts in the assembly were defined (Fig. 5.12) to guarantee the fit of the optimisation result to the seat assembly. Interfacing regions are determined as frozen regions, which are not part of the design space for optimisation. The kinematics lever is dynamically loaded if the passenger takes the sleeping position. Current topology optimisation software is limited to static load cases. Therefore the dynamic load case is simplified to five static load cases, which consider the maximum forces at different times of the dynamic seat movement. Material input for the optimisation is based on an aluminium alloy (7075) which is commonly used in aerospace industry: material density: $2810 \mathrm{~kg} / \mathrm{m}^{3}$, E Modulus: $70.000 \mathrm{MPa}$, Yield Strength: $410 \mathrm{MPa}$, Ultimate Tensile Strength: $583 \mathrm{MPa}$ and Poisson's Ratio: 0.33. The objective criterion of the optimisation is a volume fraction of $15 \%$ of the design space. The part is optimized regarding stiffness. In Fig. 5.13 the optimisation result as a mesh structure and a FEM analysis for verification of the structure are shown.

The maximum stress is approx. $300 \mathrm{MPa}$, which is below the limit of Yield Strength of $410 \mathrm{MPa}$. Before the manufacturing of the optimisation result via SLM, the surfaces get smoothened to improve the optical appearance of the part. Compared to the conventional part $(90 \mathrm{~g})$ a weight reduction of approx. $15 \%$ (final weight 77 g, Fig. 5.14) was achieved. For a series production of this part further improvements to increase the productivity of the process are needed. 


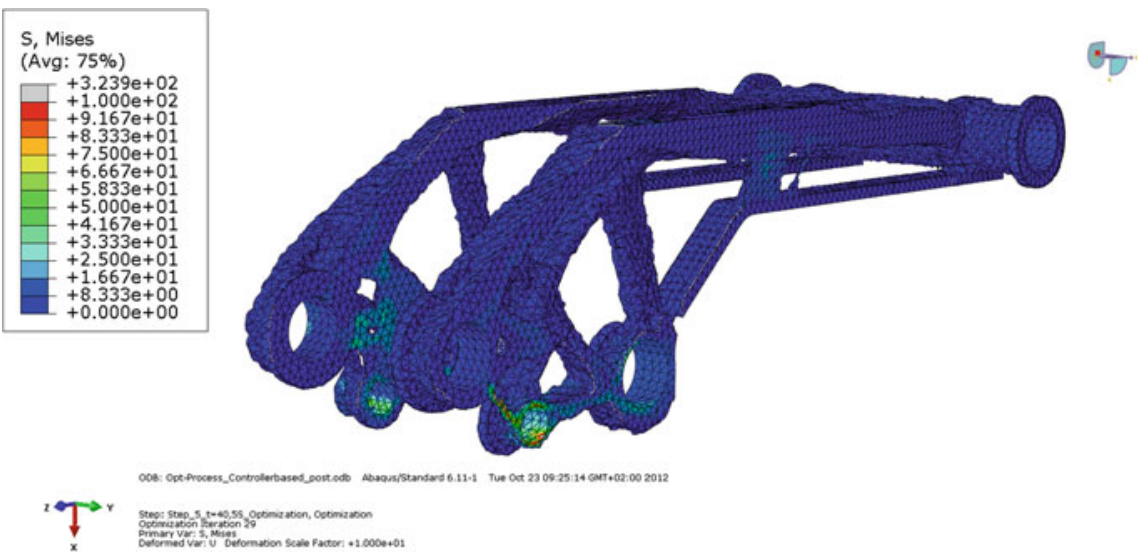

Fig. 5.13 Mesh structure of optimisation result including stress distribution

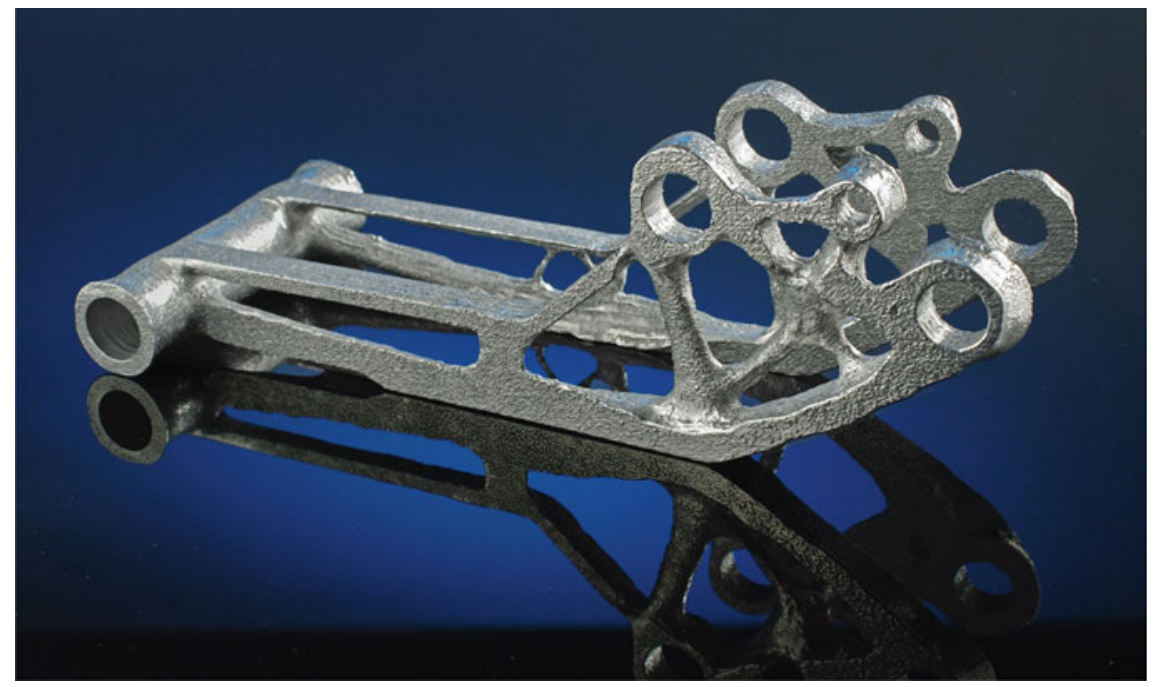

Fig. 5.14 Final light-weight part manufactured by SLM

\subsubsection{Functional Adapted Lattice Structures and SLM}

The almost unlimited freedom of design offered by SLM provides new opportunities in light-weight design through lattice structures. Due to unique properties of lattice structures (good stiffness to weight ratio, great energy absorption, etc.) and their low volume, the integration of functional adapted lattice structures in functional parts is a promising approach for using the full technology potential of SLM 


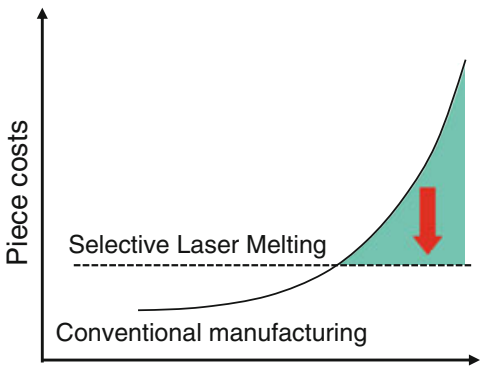

Product complexity
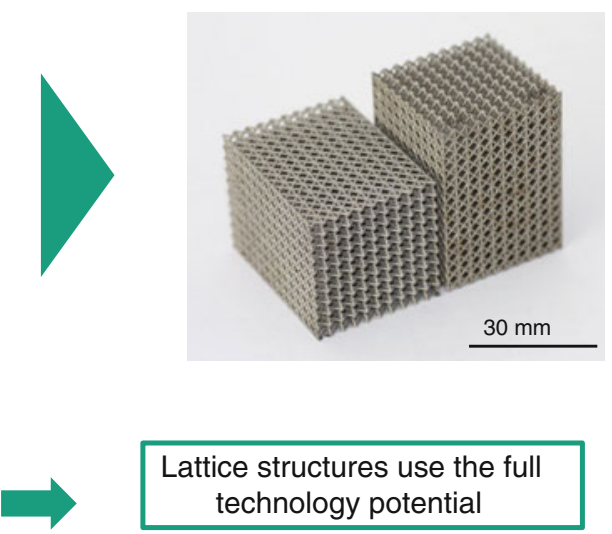

Piece costs independent of part complexity

Low volume and unique properties of lattice structures

Fig. 5.15 Complexity-for-free offers great opportunities through lattice structures

(Fig. 5.15). Compared to conventional manufacturing technologies, piece costs of SLM parts are independent of part complexity and the main cost driver is the process time (correlates with part volume). Lattice structures can reduce the amount of part volume and host unique properties.

Three main challenges need to be solved to make lattice structures a real option for the use in functional parts in different industries. The mechanical properties of different lattice structure types were studied by several researchers (Löber 2011; Shen 2010, 2012; Yan 2012; Rehme 2009; Gümrück 2013; Smith 2013; Ushijima 2011). Nevertheless, there is no comprehensive collection of mechanical properties of lattice structures under compressive, tensile, shear and dynamic load. Also the deformation and failure mechanisms are not studied sufficiently. A relatively new field of research is the influence of different scan parameters/strategies on the mechanical properties. To reach the overall objective of our research these challenges need to be overcome to design functional adapted parts with integrated lattice structures (Fig. 5.16).

As said before, the correlation between process parameters/scan strategy and mechanical properties is a new field of research. Two different scan strategies are commonly used for the fabrication of lattice structures by SLM: Contour-Hatch scan strategy and Pointlike exposure (Fig. 5.17).

Contour-Hatch scan strategy is the most commonly used scan strategy, which causes many scan vectors and jumps between scan vectors, resulting in a high amount of scanner delays. Pointlike exposure strategy reduces the complex geometry to a set of points of exposure and less jumps and scanner delays are caused. To investigate the influence of the two scan strategies on the geometry of the lattice structures, different types of f2ccz structures were manufactured. The material used in this study was stainless steel 316L (1.4404) from TLS. The parameters were iteratively optimized regarding a low geometric deviation from the 


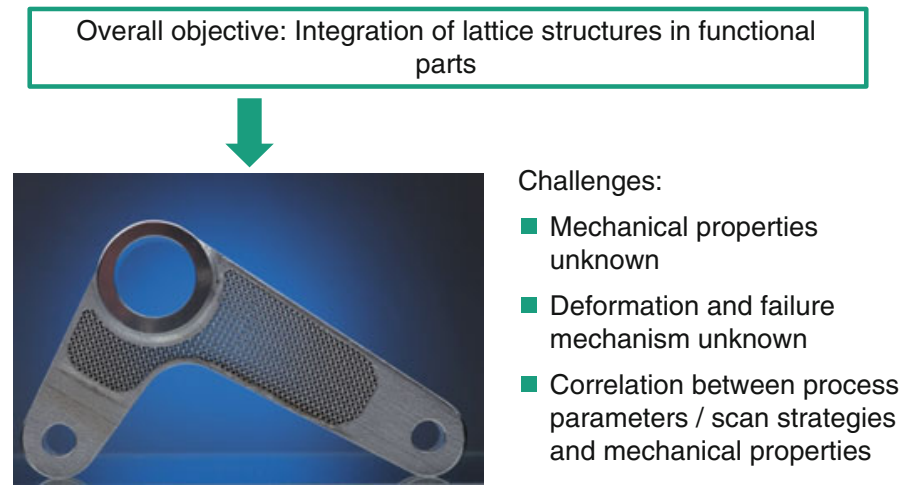

Fig. 5.16 A new way of designing functional parts by the integration of lattice structures
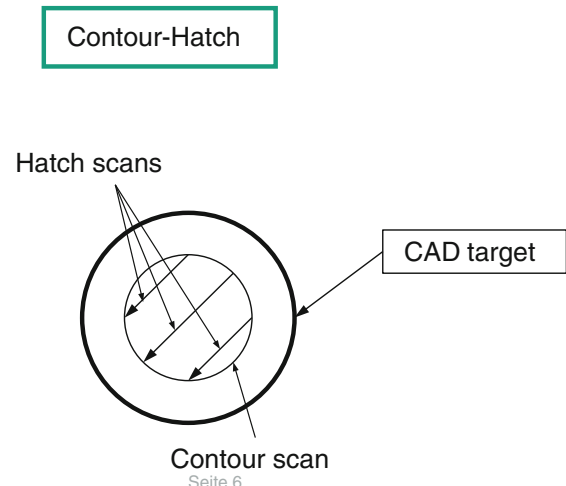

Pointlike exposure

Point of exposure

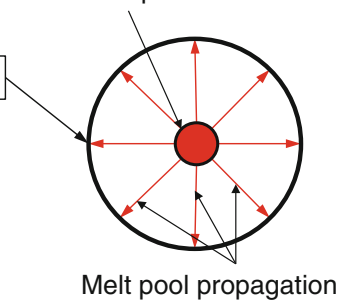

Fig. 5.17 Commonly used scan strategies for the fabrication of lattice structures

CAD model. A measurement of the relative density of the lattice structures by archimedean density measurement was performed. The relative density is the filling degree of the structure and can be used to determine geometric deviations of the structure. Three different kinds of Contour-Hatch parameters (Laser power: 100-130 W, scan speed: 700-900 mm/s) and one parameter set for Pointlike exposure (Laser power: $182 \mathrm{~W}$ ) were investigated. Figure 5.18 shows the deviations of the relative density to the CAD model target for the investigated parameters.

For Pointlike exposure strategy the relative density is $4 \%$ higher than the CAD model target. All in all, the CAD model target can be reached with low deviations. To further investigate the geometry lattice structures were investigated by micro CT measurement. Figure 5.19 shows a reconstruction based on these CT images.

Lattice structures manufactured by Contour-Hatch scan strategy show no visible build-up errors and vertical and diagonal struts have the same diameter. In contrast pointlike exposure strategy show light contractions at knots and deviations between vertical and diagonal strut diameter. 


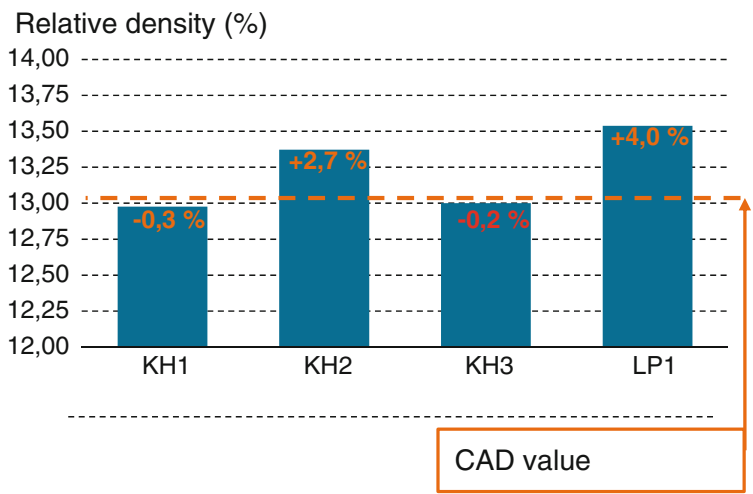

Fig. 5.18 Deviations of relative density to the CAD model target

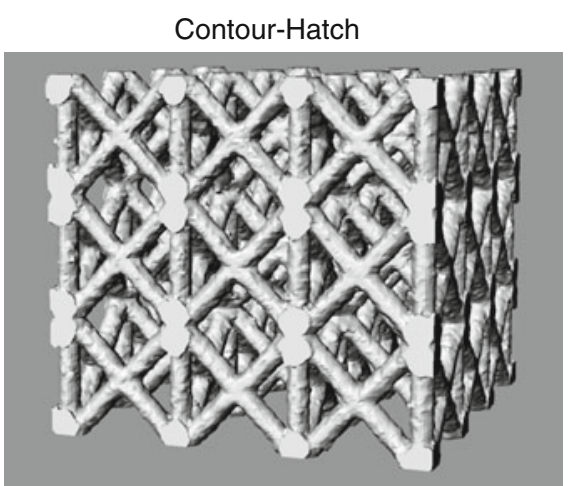

- No build-up erros

- Vertical and diagonal struts have almost same diameter

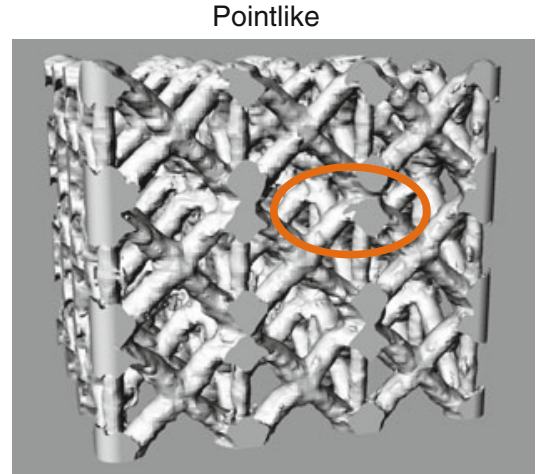

- Light contractionsat knots

- Deviations between vertical and diagonal struts

Fig. 5.19 Mirco CT reconstructions to investigate the dimensional accuracy of lattice structures

Open Access This chapter is distributed under the terms of the Creative Commons Attribution Noncommercial License, which permits any noncommercial use, distribution, and reproduction in any medium, provided the original author(s) and source are credited.

Acknowledgment The authors would like to thank the German Research Foundation DFG for the kind support within the Cluster of Excellence "Integrative Production Technology for HighWage Countries. 


\section{References}

Concept Laser (2014) Data sheet X line 1000R. http://platforms.monash.edu/mcam/images/stories/ Concept/xline_1000.pdf Accessed 02.10.2014

Economist (2011) Cover Story, 12.2.2011

Gibson I et al (2010) Additive Manufacturing Technologies. Rapid Prototyping to Direct Digital Manufacturing, Springer, Heidelberg

Gümrük R, Mines R A W (2013) Compressive behaviour of stainless steel micro-lattice structures, International Journal of Mechanical Sciences, 2013

Hopkinson N et al (eds) (2005) Rapid Manufacturing: An Industrial Revolution for the Digital Age. Wiley

Huang X, Xie M (2010) Evolutionary Topology Optimisation of Continuum Structures: Methods and Applications. Wiley

Lindemann U (eds) (2006) Individualisierte Produkte - Komplexität beherrschen in Entwicklung und Produktion, Springer, Heidelberg

Lindemann C et al (2012) Analyzing Product Lifecycle Costs for a Better Understanding of Cost Drivers in Additive Manufacturing. In: Proceedings of "International Solid Freeform Fabrication Symposium 2012", Austin Texas

Löber L, Klemm D, Kühn U, Eckert, J (2011) Rapid Manufacturing of Cellular Structures of Steel or Titaniumalumide, MSF (Materials Science Forum), Vol. 690, 2011

Meiners W (1999) Direktes Selektives Lasersintern einkomponentiger metallischer Werkstoffe. Dissertation, RWTH Aachen

Over C (2003) Generative Fertigung von Bauteilen aus Werkzeugstahl X38CrMoV5-1 und Titan TiAL6V4 mit „Selective Laser Melting“. Dissertation, RWTH Aachen

Rehme O (2009) Cellular Design for Laser Freeform Fabrication, PhD Thesis, Laser Zentrum Nord, Hamburg

Rickenbacher L (2013) An integrated cost-model for selective laser melting. Rapid Prototyping Journal, Vol. 19 Number 3 2013, pp. 208-214

Schleifenbaum H, Meiners W, Wissenbach K (2008) Towards Rapid Manufacturing for series production: an ongoing process report on increasing the build rate of Selective Laser Melting (SLM). International Conference on Rapid Prototyping \& Rapid Tooling \& Rapid Manufacturing, Berlin, Germany

Schleifenbaum $\mathrm{H}$ et al (2010) Individualized production by means of high power Selective Laser Melting. CIRP Journal of Manufacturing Science and Technology, vol 2 (3), pp. 161-169

Schleifenbaum $\mathrm{H}$ et al (2011) Werkzeuglose Produktionstechnologien für individualisierte Produkte. In: Brecher C (eds) Integrative Produktionstechnik für Hochlohnländer, Springer

Shen Y, McKown S, Tsopanos S, Sutcliffe C J, Mines R A W, Cantwell W J (2010) The Mechanical Properties of Sandwich Structures Based on Metal Lattice Architectures, Journal of Sandwich Structures and Materials, Vol. 12, 2010

Shen Y, Cantwell W J, Mines R A W, Ushijima K (2012) The Properties of Lattice Structures Manufactured Using Selective Laser Melting, AMR (Advanced Materials Research), Vol. 445, pp. 386-391, 2012

SLM Solutions (2014) Data sheet SLM500HL. http://www.stage.slm-solutions.com/download. php?f=8277396e9b97045edbb7ef680e3ada56 Accessed 02.10.2014

Smith M, Guan Z, Cantwell W J (2013) Finite element modelling of the compressive response of lattice structures manufactured using the selective laser melting technique, International Journal of Mechanical Sciences, 2013

Ushijima K, Cantwell W J, Mines R A W, Tsopanos S, Smith M (2011) An investigation into the compressive properties of stainless steel micro-lattice structures, Journal of Sandwich Structures and Materials, 2011

Yan C, Hao L, Hussein A, Raymont D (2012) Evaluations of cellular lattice structures manufactured using selective laser melting, International Journal of Machine Tools and Manufacture, Vol 62, pp. 32-38, 2012 